\title{
Treatment of small cell lung carcinoma in association with cryptogenic fibrosing alveolitis
}

\author{
J. R. LIPTON* \\ M.B., Ch.B. \\ K. Carroll $\dagger$ \\ M.R.C.P. \\ J. J. MOULD* \\ F.R.C.R. \\ J. WINSTANLEY*
M.B., Ch.B. \\ N. THATCHER* \\ Ph.D., M.R.C.P. \\ *Cancer Research Campaign, Department of Medical Oncology, University of Manchester, and \\ †Department of Chest Medicine, Wythenshawe Hospital, Manchester
}

\begin{abstract}
Summary
Two patients with small cell bronchogenic carcinoma associated with cryptogenic fibrosing alveolitis are described. Both patients received radiotherapy and i.v. chemotherapy with moderate dose methotrexate $\left(100 \mathrm{mg} / \mathrm{m}^{2}\right)$ and escalating high dose cyclophosphamide $\left(1.5 \mathrm{~g}, 2.5 \mathrm{~g}, 3.5 \mathrm{~g} / \mathrm{m}^{2}\right)$.

Good symptomatic improvement was obtained with concurrent tumour response. No effect upon the alveolitis was observed. The pulmonary toxicity associated with methotrexate, cyclophosphamide chemotherapy and radiotherapy is described. The use of immunosuppressive agents (including cytotoxic drugs) to improve fibrosing alveolitis is also discussed

There is no apparent contraindication for intensive antitumour therapy in patients with small cell lung cancer and fibrosing alveolitis.
\end{abstract}

\section{Introduction}

Lung cancer is known to arise in relation to pulmonary scars (Matthews 1974); more recently an excess risk has been reported of developing bronchogenic carcinoma in patients with cryptogenic fibrosing alveolitis (Turner-Warwick et al., 1980). The distribution of the histological types of carcinoma is similar to that of patients without fibrosis (Stack, Choo-Kang and Heard, 1972; Turner-Warwick et al., 1980).

Palliative megavoltage radiotherapy given for lung carcinoma is not usually associated with noticeable pulmonary fibrosis when conventional doses are prescribed (Weir and Michaelson, 1971). The prognosis of patients with small cell lung cancer has appreciably improved with modern chemotherapy (Livingston, 1980). It is being increasingly recognized, however, that some cytotoxic agents may themselves cause lung damage (Collis, 1980).

Corticosteroids have been extensively used with variable efficacy in the treatment of cryptogenic fibrosing alveolitis. Other immunosuppressive agents including cytotoxic drugs (azathioprine, cyclo@ phosphamide) are under investigation as potentiak treatment for fibrosing alveolitis (Crystal et al. 1976; Plowman and Stableforth, 1977).

An interesting paradox then occurs when chemotherapy is given to patients with small cell lung cancer and co-existing cryptogenic fibrosing alveolitis. The chemotherapy could aggravate the alveolitis or conversely retard or improve the fibrotic change.

The clinical course of two patients with small cell lung cancer and cryptogenic fibrosing alveolitis treated with chemotherapy and irradiation is described.

\section{Case reports}

No. 1

A labourer presented in June 1980 when 48 years old with a 3-month history of increasing breathlessness on exertion and a dry irritating cough. Examination revealed gross finger clubbing (noted by the patient in 1970) right supraclavicular lymphadenopathy and end inspiratory crepitations at both lung bases.

A chest X-ray showed a large left hilar shadow with widening of the superior mediastinum and increased peripheral lung markings at the bases. Bronchoscopy and biopsy confirmed carcinoma of the left upper lobe (LUL) bronchus of small cell type. Pretreatment lung function studies indicated 
a restrictive pattern with reduction in vital capacity, transfer factor, and hypoxaemia.

\section{No. 2}

A 60-year-old housewife presented in August 1980 with a 4-month history of cough, haemoptyses, breathlessness and occasional wheezing. Examination was unremarkable except for finger clubbing and end inspiratory crepitations over both lung bases. A left hilar mass was seen on chest X-ray with increased lung markings throughout both lung fields particularly in the left lower zone. Bronchoscopy and biopsy demonstrated a carcinoma of the LUL bronchus, of small cell type. A chest X-ray taken 2 years before for investigation of dry cough showed similar diffuse pulmonary mottling but without hilar enlargement. Lung function tests now demonstrated a restrictive defect with marked decrease in total lung capacity and transfer factor.

Neither patient had been exposed to agents known to cause pulmonary fibrosis before antitumour therapy was begun. Both patients had smoked 30 to 40 cigarettes each day for more than 20 years; exercise tolerance was severely restricted before treatment with extreme dyspnoea on walking 50 yards on the flat. The peripheral blood count, urea, electrolytes, biochemical profile, including liver function tests, serum immunoglobulins, autoantibody screen, rheumatoid factor and anti-DNA levels were all within the normal range.

\section{Treatment}

The treatment protocol consisted of two i.v. bolus injections of methotrexate $100 \mathrm{mg} / \mathrm{m}^{2}$, no folinic acid being required, at a 2-week interval. Mediastinal irradiation (4MV) encompassing ob- vious tumour started the day after the 2 nd injection of methotrexate; 8 daily fractions by parallel pair fields $(12 \times 10 \mathrm{~cm})$ to $3100 \mathrm{cGy}$ tumour dose was given.

Two weeks after the final fraction of radiotherapy escalating high-dose cyclophosphamide was administered i.v. at $1.5 \mathrm{~g} / \mathrm{m}^{2}$ proceeding to $2.5 \mathrm{~g}$ and $3.5 \mathrm{~g} / \mathrm{m}^{2}$ at 3-week intervals. Since the third dose of cyclophosphamide no further chemotherapy has been given.

The pulmonary function studies (Table 1) showed no marked change when the pre-treatment values were compared with the test values, obtained after irradiation (but before cyclophosphamide), one month and four months after the last cyclophosphamide injection. Examination of chest radiographs showed no marked increase in the fibrosis (outside the radiotherapy field) when the pre-treatment films were compared with the films taken 4 months after the last administration of cyclophosphamide (Figs $1 \& 2$ ).

\section{Discussion}

Chemotherapy for small cell lung cancer is now an established practice (Livingston, 1980). Although the risk of lung cancer is increased in patients with cryptogenic fibrosing alveolitis (Turner-Warwick et al., 1980), there are no reports of the effect of anti-cancer therapy upon the alveolitis. The diagnosis of cryptogenic fibrosing alveolitis in the two patients was based upon characteristic clinical and radiological features. The initial pulmonary function also indicated a fibrosing disorder; lung biopsy for histological confirmation was not considered indicated.

Lung damage following cytotoxic therapy was

TABLE 1. Serial lung function tests of patients (predicted values in parentheses for patient 1 and 2 respectively)

\begin{tabular}{|c|c|c|c|c|c|c|c|c|}
\hline & \multicolumn{2}{|c|}{ Pre-Mtx } & \multicolumn{2}{|c|}{$\begin{array}{l}\text { Post-XRT } \\
\text { Pre-Cy }\end{array}$} & \multicolumn{2}{|c|}{$\begin{array}{l}\text { Post-Cy } \\
1 \text { month }\end{array}$} & \multicolumn{2}{|c|}{$\begin{array}{l}\text { Post-Cy } \\
4 \text { months }\end{array}$} \\
\hline & No. 1 & No. 2 & No. 1 & No. 2 & No. 1 & No. 2 & No. 1 & No. 2 \\
\hline VC & & & & & & & & \\
\hline $\begin{array}{c}(4 \cdot 4 ; 3 \cdot 4 \text { litres }) \\
\text { FEV }_{1}\end{array}$ & $3 \cdot 3$ & $2 \cdot 1$ & $4 \cdot 1$ & $2 \cdot 5$ & 3.9 & $2 \cdot 2$ & $3 \cdot 7$ & $2 \cdot 0$ \\
\hline $\begin{array}{l}(3 \cdot 4 ; 2 \cdot 2 \text { litres }) \\
\text { TLC }\end{array}$ & $2 \cdot 7$ & 1.9 & $3 \cdot 0$ & $2 \cdot 1$ & $2 \cdot 9$ & 1.9 & $2 \cdot 5$ & $1 \cdot 7$ \\
\hline $\begin{array}{l}(5 \cdot 5 ; 4 \cdot 2 \text { litres }) \\
\text { TF }\end{array}$ & $5 \cdot 1$ & 3.9 & $6 \cdot 4$ & $3 \cdot 7$ & $6 \cdot 3$ & $3 \cdot 5$ & $5 \cdot 2$ & $3 \cdot 3$ \\
\hline $\begin{array}{c}(29 ; 22 \cdot 3 \mathrm{ml}) \\
\mathrm{KCO}\end{array}$ & $12 \cdot 1$ & $10 \cdot 1$ & 11.9 & $10 \cdot 5$ & $14 \cdot 4$ & $10 \cdot 0$ & $12 \cdot 9$ & $9 \cdot 6$ \\
\hline$(4 \cdot 7 ; 4.9 \mathrm{ml})$ & $2 \cdot 6$ & $3 \cdot 4$ & $2 \cdot 6$ & $3 \cdot 6$ & $3 \cdot 0$ & $3 \cdot 5$ & $2 \cdot 7$ & 3.5 \\
\hline $\mathrm{PO}_{2}$ & 67 & 71 & 65 & 74 & 59 & 70 & 61 & 70 \\
\hline $\begin{array}{l}P_{\mathrm{CO}_{2}} \\
\text { Exercise tolerance on the flat }\end{array}$ & 39 & 40 & 39 & 41 & 49 & 39 & 54 & 40 \\
\hline (yards) & 50 & 50 & 200 & 200 & 500 & 200 & 500 & 100 \\
\hline
\end{tabular}

Mtx, methotrexate; Cy, cyclophosphamide; XRT, radiotherapy; VC, vital capacity; FEV , forced expiratory volume, 1 second; TLC, total lung capacity; TF, transfer factor $(\mathrm{ml} / \mathrm{CO} / \mathrm{min} / \mathrm{mmHg}) ; \mathrm{KCO}$, gas transfer per unit volume lung (ml/CO/ $\mathrm{min} / \mathrm{mmHg} / \mathrm{l})$ : arterial $\mathrm{PO}_{2}$, arterial $\mathrm{PCO}_{2}$, partial gas pressures $(\mathrm{mmHg})$. 


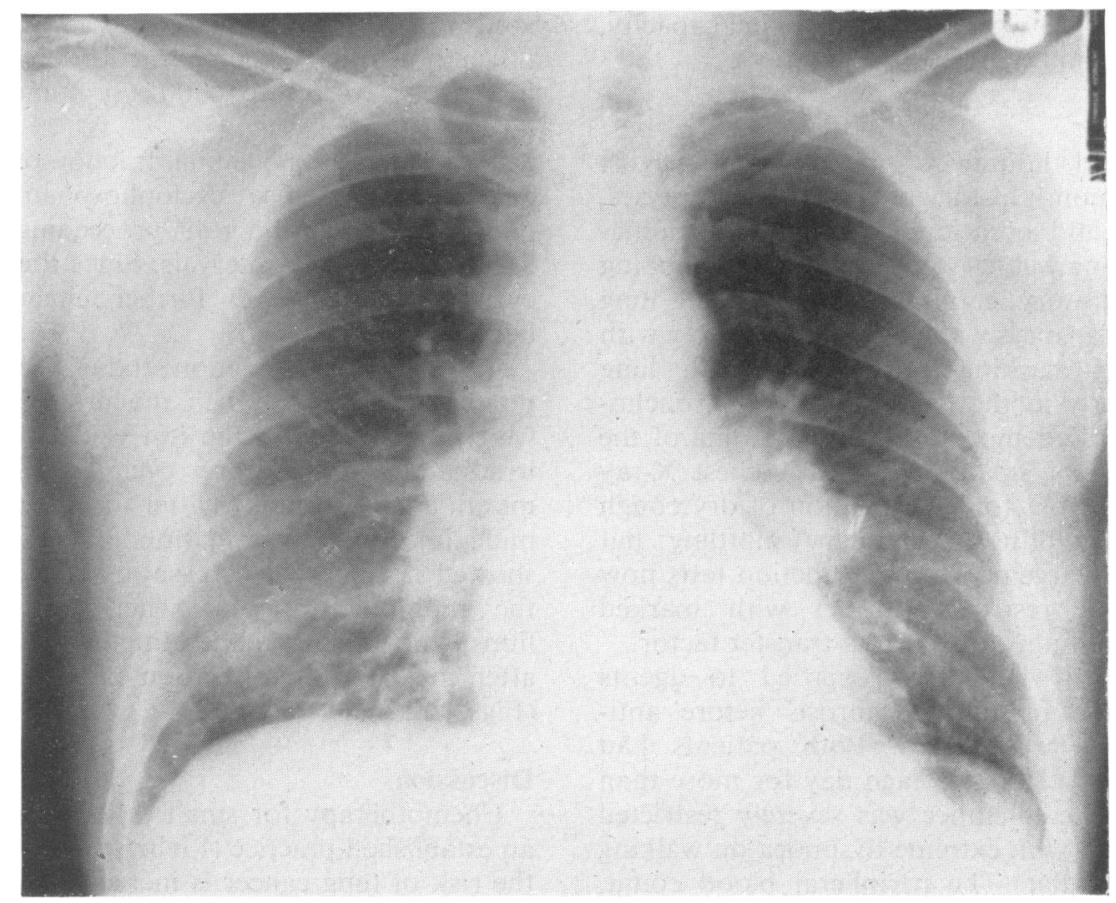

FIG. 1. Pretreatment chest, patient X-ray, patient No. 1.

unrecognized until 1961 (Collis, 1980) and lung toxicity has been reported with a measurable frequency only with bleomycin, busulphan and methotrexate (Collis, 1980).

Chemotherapeutic agents causing pulmonary toxicity can be broadly divided into two groups. Pulmonary changes of insidious onset have been observed months to many years after exposure to drugs such as busulphan and cyclophosphamide. The other group represented by methotrexate produces an illness of sudden onset following a short exposure to the drug and with methotrexate there can be a peripheral blood eosinophilia (Collis, 1980).

Methotrexate lung damage has been noted over a wide dose-range including $100 \mathrm{mg} / \mathrm{m}^{2}$ used in the present study. The incidence is independent of dose or duration of treatment and enhancement of radiation pneumonitis has not been reported (Collis, 1980). Cyclophosphamide-induced lung damage has been described in patients receiving continuous low-dose therapy (Willson, 1978).

The two patients did not experience exacerbation of any symptoms suggestive of drug induced lung damage. There was some increase in shadowing on the chest radiograph but this occurred within the irradiated field and was unassociated with any increase in lung markings elsewhere. The pulmonary function tests in the two patients showed no marked change with treatment; in particular there was noD obvious increase in the restrictive ventilatory defect nor in the diffusion defect that is associated with radiation lung damage. It is interesting that even the high doses of cyclophosphamide com parable to those used in bone marrow transplantation were not associated with obvious pulmonary damages and a relationship of dose to lung toxicity was. not obvious. In other patients treated for broncho 3 . genic carcinoma, an increase in vital capacity residual volume and $\mathrm{FEV}_{1}$ (particularly if at pre 3 sentation marked airways obstruction was evident $b$ is commonly found soon after the start of irradiation? followed by a slow decline with ultimate stabilization at or just below pretreatment values; the diffusing capacity for $\mathrm{CO}$ usually decreases after irradiations in the majority of patients (Bousky, Helgasan, and North, 1970; Weir and Michaelson, 1971). Although the patients' symptoms improved following tumou' regression there was some decrease in the diffusing capacity for $\mathrm{CO}$ but the lung volumes in the tw\& patients were largely unchanged, probably repre senting the restriction imposed by the pre-existing lung fibrosis. Unfortunately there is no firm correla tion between radiography, pulmonary functior 


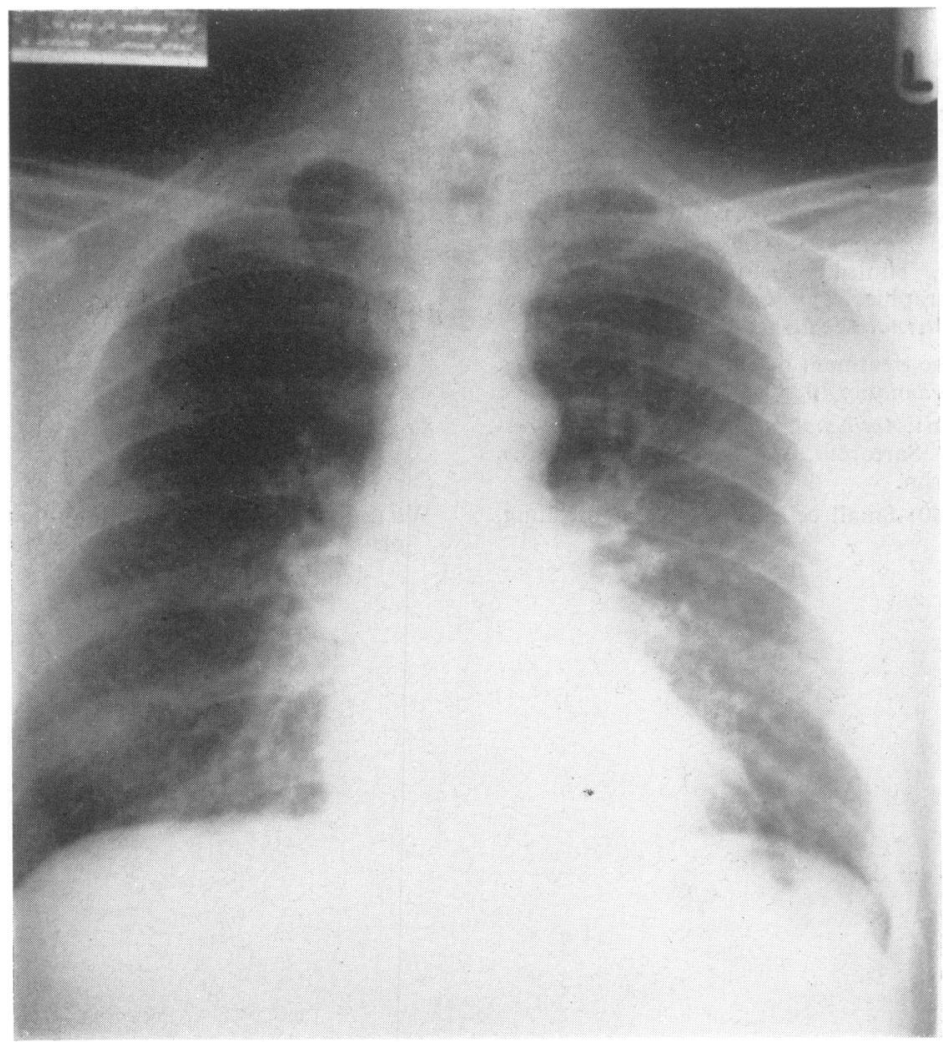

FIG. 2. Four months post-treatment chest, X-ray, patient No. 1.

studies and symptoms in patients with cryptogenic fibrosing alveolitis (Crystal et al., 1976), and a similar problem is present in the serial follow-up of patients receiving agents potentially toxic to the lungs.

Clinical symptoms attributable to a radiation lung reaction in patients irradiated for bronchogenic carcinoma are unusual but the radiographic evidence of fibrosis increases with time, individual susceptability being a marked feature (Deeley, 1967). No convincing evidence exists in humans that a reaction occurs in unexposed areas of irradiated lung (Weir and Michaelson, 1971). There is no definite clinical evidence of a harmful interaction on lung tissue, between methotrexate and cyclophosphamide and irradiation, although this is not so for other cytotoxic drugs particularly in the case of the antitumour antibotics (Phillips and $\mathrm{Fu}, 1976$ ).

An attempt has been made to improve the clinical course of patients with cryptogenic fibrosing alveolitis, in which the average untreated survival is 4 years, by deliberate immunosuppression, with antimetabolites (Crystal et al., 1976). Plowman and Stableforth (1977) described improvement with cyclophosophamide in a patient with fibrosing alveolitis which was progressing despite steroids. In the present two patients, no improvement in lung function studies or chest radiographs as regards the pre-existing fibrosis was evident: the improvement in the patients' symptoms was considered to be a result of tumour regression. The scheduling of the intermittent chemotherapy in the present report would, however, be less immunosuppressive (Hersh, 1974) and possibly, therefore, less effective in controlling the alveolitis than the continuous administration described by Plowman and Stableforth (1977).

It would seem reasonable that pre-existing lung disease would reduce the tolerance of the lung to irradiation and drug toxicity, but there was no evidence of untoward toxicity in the present two patients with small cell lung cancer and cryptogenic fibrosing alveolitis. There is no apparent contraindication to the use of intensive chemotherapy and radiotherapy in this clinical situation. 


\section{References}

Bousky, S.F., Helgasan, A.H. \& North, L.B. (1970) The effect of radiation on the lung and bronchial tree. American Journal of Roentgenology and Radium Therapy, 108, 284.

Collis, C.H. (1980) Lung damage from cytotoxic drugs. Cancer Chemotherapy and Pharmacology, 4, 17.

Crystal, R.G., Fulmer, J.D., Roberts, W.C., Morton, M.L. Line, B.R. \& ReYNolds, H.Y. (1976) Idiopathic pulmonary fibrosis, clinical, histologic, radiographic, physiologic, scintigraphic, cytologic and biochemical aspects. Annals of Internal Medicine, 85, 769.

DEELEY, T.J. (1967) The treatment of carcinoma of the lung. British Journal of Radiology, 40, 801.

HERSH, E.M. (1974) In: Antineoplastic and Immunosuppressive Agents (Ed by Sartorelli, A. C. \& Johns, D. G.), p. 577. Springer, Berlin.

Livingston, R.B. (1980) Small cell carcinoma of the lung. Blood, 56, 575.
Matthews, M.J. (1974) Morphology of lung cancer $\frac{\Omega}{\Phi}$ Seminars in Oncology, 4, 175.

Phillips, T.K. \& FU, K.K. (1976) Quantification of combined radiation therapy and chemotherapy. Effects on critical; normal tissues. Cancer, 37, 1186.

Plowman, P.N. \& Stableforth, D.E. (1977) Dermato myositis with fibrosing alveolitis. Response to treatment with cyclophosphamide. Proceedings of The Royal Societ $\overline{\bar{S}}$ of Medicine, 70, 738.

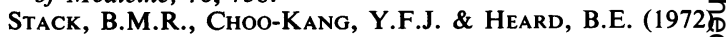
The prognosis of cryptogenic fibrosing alveolitis. Thorax, 27, 535.

TURNER-WARWICK, M., Lebowitz, M., Burrows, B. \& JoHnson, A. (1980) Cryptogenic fibrosing alveolitis an $\varnothing$ lung cancer. Thorax, 35, 496.

Weir, G.J. \& Michaelson, S.M. (1971) In: Pulmonar $\vec{w}$ Radiation Reactions, pp. 27-35; 51-52. C.C. Thomas? Chicago, Illinois, U.S.A.

WILlSON, J.K.V. (1978) Pulmonary toxicity of antineo plastic drugs. Cancer Treatment Reports, 62, 2003. 